4th International Scientific Conference SEC-IASR 2019,

Galati, Romania, 7th - 8th June, 2019

\title{
Visual Choice Reaction Time in Schoolchildren Aged 12-14 Years Old. Comparison between Trained and Untrained Children
}

\author{
Diana Victoria GIDU, George Cosmin MUŞAT \\ https://doi.org/10.18662/lumproc/sec-iasr2019/17
}

How to cite: Gidu, D.V., \& Muşat, G.C. (2020). Visual Choice Reaction Time in Schoolchildren Aged 12-14 Years Old. Comparison between Trained and Untrained Children. In S. Marin \& P. Moisescu (vol. eds.), Lumen Proceedings: Vol. 12. 4th International Scientific Conference SEC-LASR 2019 (pp. 151-159). Iasi, Romania: LUMEN Publishing House.

https://doi.org/10.18662/lumproc/sec-iasr2019/17 


\title{
Visual Choice Reaction Time in Schoolchildren Aged 12-14 Years Old. Comparison between Trained and Untrained Children
}

\author{
Diana Victoria GIDU1*, George Cosmin MUŞAT² \\ Abstract
}

The purpose of the work was to study if there is any difference in visual choice reaction time [VCRT] between the children who practice sports and non-sporting children, and if the performance depends on the gender and design of the testing: continuous [50 and 100 trials] versus sequential [10 trials each sequence, with 30 sec. rest between sequences].

The 20 non-sporting children [10 girls and 10 boys] were tested only continuously but the 20 sporting ones [10 girls and 10 boys] were tested both continuously and sequentially. While testing the subjects were using their preferred hand.

The results support the conclusion that while there is no difference between girls and boys, VCRT in sporting children is significantly better, than in non-sporting ones, both in girls [657.84 \pm 70.02 vs $760.77 \pm 112.82 \mathrm{~ms} ; p<0.05]$ and boys [698.67 \pm 65.27 vs $833.09 \pm 102.36$ $m s ; p<0.01]$. On the other hand, in atbletes the results obtained within the 100 trials sequential testing were significantly better than in the continuous testing.

Keywords: visual choice reaction time; gender comparison; trained and untrained children.

\footnotetext{
${ }^{1}$ Ovidius University of Constanta, Constanta, Romania, campiap@yahoo.com.

${ }^{2}$ Ovidius University of Constanta, Constanta, Romania, musat grg@yahoo.com. 


\section{Introduction}

It is known that the reaction rate expresses the duration of a cycle of physiological and biochemical processes that occur after a stimulus, followed by a response [2].

In a very rigorous manner, reaction rate is a component of reaction time, and what is currently being tested in psychology laboratories is precisely this 'reaction time'. It is defined as the speed at which an individual can react and move. The reaction time is, in particular, the total time elapsed from the occurrence of the stimulus to the task accomplishment, and has two components:

- reactiontime (RT)- the time elapsed from the stimulus occurrence to the initiation of the motion, and

- motion-execution time -which begins when the reaction time ends and represents the elapsed time from the beginning of the motion to the actual execution of the task.

In turn, the reaction rate is divided into perception time (of the stimulus) and decision time (for decision-making) [4],[8].

Depending on the type of stimulus, RT can be as follows:

- visual RT -when the stimulus is visual;

- auditory RT-when the stimulusis acoustic;

- sensorial/cutaneous RT-when the stimulus is sensorial, and also,

- simple RT (SRT) -when there is only one response for a stimulus, which does not require time to elaborate, and

- complex RT(by choice) (CRT) -when for a particular stimulus, the response needs to be elaborated and selected from several possibilities [7]

\section{Problem Statement}

CRTis one of the dependent variables widely used in experimental psychology. Of course, this is due to the fact that CRT is an important element of human performance, being defined as the minimum time needed to identify the stimulus and initiate the appropriate response [9],[10].

Different authors have concluded that RT values (simple or complex) differ in sporting persons compared to non-sporting persons, which are lower in the case of the first ones[5],[6],[12].

Taking as a starting point both this remark and the one detached from the previous work [3] (which found that in sportschildren aged 12-14, gender 
differences are insignificant), we have proposed to put 'face to face' two groups of children in this study; some of them are trained, while the others are untrained. On the other side, since the subjects in the literature we have studied were 16 to 25 years old, we found it interesting to carry out this study, in which we will compare RT values of trained and untrained children (boys and girls), at the age group of 12-14 years.

\section{Research Questions/Aims of the research}

More specifically, the study aims to observe whether or not there are differences in RT values for trained children compared to untrained ones, namely in girls and boys; and also if the division of the task (to be done) into sequences of 10 tests with pause between them influences RT or not.

\section{Research Methods}

The study was conducted on a group of 40 pupils, i.e. 20 girls and 20 boys, from N. TonitzaMiddle School in Constanta. Of them, 10 girls and 10 boys regularly practiced a sport (handball, 5 days a week for 2 hours, doing about 230 training sessions per calendar year) and had a 20 -month training experience. The remaining 10 girls and 10 boys only attended the physical education classes ( 2 hours per week). However, most of the girls in this last group have been dally with various sports for 3-5 months, but at the time of testing, only one of them was still 'active' (dancesport).

Table 1.Average age of subjects

\begin{tabular}{lll}
\hline trained / un-trained & gender & age (years) \\
\hline \multirow{2}{*}{ trained } & girls & $13.10 \pm 0.56$ \\
\cline { 2 - 3 } & boys & $12.90 \pm 0.62$ \\
\multirow{2}{*}{ un-trained } & girls & $13.00 \pm 0.00$ \\
& boys & $13.18 \pm 0.60$ \\
\hline
\end{tabular}

RT was recorded using an own design device, which has already been presented in a previous paperwork [3]. To adapt to the device, each subject executed a series of 50 tests on the testing day. The test itself consisted of a second series of tests (one of 50 tests and the other of 100 tests) for both the handball players and the others. Besides these, the handball subjects also performed two more series (50 and 100 tests respectively), broken down into sequences of 10, with a 30 second rest 
between the sequences. As in the previous study, participants were required to use their skilled hand to manipulate the keyboard.

The subjects were divided into four separate groups:

- trained girls

- untrained girls

- trained boys

- untrained boys

At the time of testing, each of these four groups was randomly divided into two subgroups. Half of the members of the subgroup performed the series of 50 tests, and the other half, the series of 100 tests. At the next testing session, the subgroups reversed the task. This subdivision of the samples was made to remove the effect of the test order.

Appropriate handling and testing was done on different days and always after classes for both groups of subjects. For objective reasons, the untrained pupils were tested between 12 and 13 and the trained ones later: the girls between 13 and 15 and the boys between 15 and 17.

Statistically, apart from the calculation of standard mean and deviations, the groups of subjects were compared (gender comparison and same gender comparison). All meanings were considered at the minimum threshold of 0.05 .

\section{Findings}

Table 2.RT for 50 and 100 tests (ms)

\begin{tabular}{|c|c|c|c|c|c|}
\hline \multicolumn{2}{|c|}{ trained / un-trained } & \multicolumn{2}{|c|}{ Continuous testing } & \multicolumn{2}{|c|}{$\begin{array}{l}\text { Sequential testing } \\
10 \text { tests }\end{array}$} \\
\hline & & 50 tests & 100 tests & 50 tests & 100 tests \\
\hline \multirow{4}{*}{ trained } & \multirow{2}{*}{ girls } & $657.84^{\mathrm{ac}}$ & 674.00 & 669.67 & $651.25^{\mathrm{d}}$ \\
\hline & & \pm 70.02 & \pm 83.93 & \pm 57.41 & \pm 52.14 \\
\hline & & $698.67^{b}$ & $711.83^{b}$ & 705.43 & 662.82 \\
\hline & boys & \pm 65.27 & \pm 31.05 & \pm 73.24 & \pm 66.42 \\
\hline \multirow{2}{*}{ un-trained } & girls & $\begin{array}{l}760.77 \\
\pm 112.82\end{array}$ & $\begin{array}{l}720.82 \\
\pm 108.82\end{array}$ & 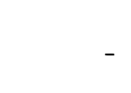 & 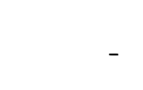 \\
\hline & boys & $\begin{array}{l}833.09 \\
\pm 102.36\end{array}$ & $\begin{array}{l}783.48 \\
\pm 98.46\end{array}$ & - & - \\
\hline
\end{tabular}

$\mathrm{a}-$ significant difference from untrained girls $(\mathrm{p}<0.05)$

$\mathrm{b}-$ significant difference from untrained boys $(\mathrm{p}<0.05)$

$\mathrm{c}-$ significant difference from series of 50 sequential tests $(\mathrm{p}<0.05)$

$\mathrm{d}-$ significant difference from series of 100 consecutive tests $(\mathrm{p}<0.05)$ 
Diana Victoria GIDU \& ... | Lumen Proceedings 12 | SEC-IASR 2019

Table 3. RT by groups of 50 tests, within consecutive testing (ms)

\begin{tabular}{lllll}
\hline \multirow{2}{*}{ trained / un-trained } & 50 tests & \multicolumn{2}{c}{100 tests } \\
\cline { 3 - 5 } & \multirow{2}{*}{50 tests } & $\begin{array}{l}\text { first group } 50 \\
\text { tests }\end{array}$ & $\begin{array}{l}\text { second group } \\
50 \text { tests }\end{array}$ \\
\hline \multirow{4}{*}{ trained } & girls & $657.84^{\mathrm{a}}$ & 662.27 & 686.88 \\
& & \pm 70.02 & \pm 98.27 & \pm 76.72 \\
& boys & $698.67 \mathrm{a}$ & $688.44^{\mathrm{b}}$ & 726.33 \\
& & \pm 65.27 & \pm 55.19 & \pm 53.73 \\
un-trained & girls & 760.77 & $709.12^{\mathrm{b}}$ & 732.88 \\
& & \pm 112.82 & \pm 117.52 & \pm 104.61 \\
& \multirow{2}{*}{ boys } & 833.09 & $766.58^{\mathrm{b}}$ & 799.79 \\
& & \pm 102.36 & \pm 105.48 & \pm 95.12 \\
\hline
\end{tabular}

a - significant difference from the second group of 50 tests out of $100(p<0.01)$

$\mathrm{b}-$ significant difference from the series of 50 consecutive tests $(\mathrm{p}<0.01)$

Table 4. RTby groups of 50 tests, within 10 sequential tests (ms)

\begin{tabular}{|c|c|c|c|}
\hline \multirow[b]{2}{*}{ Gender } & \multirow{2}{*}{$\begin{array}{l}50 \text { tests } \\
50 \text { tests }\end{array}$} & \multicolumn{2}{|c|}{100 tests } \\
\hline & & $\begin{array}{ll}\text { first group } & 50 \\
\text { tests } & \end{array}$ & $\begin{array}{l}\text { second group } 50 \\
\text { tests }\end{array}$ \\
\hline girls & $\begin{array}{l}669.67 \\
\pm 57.41\end{array}$ & $\begin{array}{l}651.82^{a} \\
\pm 56.98\end{array}$ & $\begin{array}{l}650.69 \\
\pm 52.22\end{array}$ \\
\hline boys & $\begin{array}{l}705.43 \\
\pm 73.24\end{array}$ & $\begin{array}{l}667.02^{\mathrm{a}} \\
\pm 76.53\end{array}$ & $\begin{array}{l}658.63 \\
\pm 67.67\end{array}$ \\
\hline
\end{tabular}

a - significant difference from the series of 50 sequential tests $(\mathrm{p}<0.01)$

\section{Discussions}

Comparing the results by gender showed that there was no significant difference in any tests between girls and boys playing handball and girls and boys who participated only in physical education classes( $\mathrm{p}>0.05 ;$ Tab.2).

In contrast, comparing the results of the sporting girls with those of the non-sporting girls and those of the sporting boys with the non-sporting boys, we found that in the case of the 50 tests, the differences recorded were significant $(\mathrm{p}<0.05)$, meaning that the values obtained by sporting children $(657.84 \pm 70.02 \mathrm{~ms}$ for girls and $698.67 \pm 65.27 \mathrm{~ms}$ for boys) were 
significantly lower than those of non-sporting children $(760.77 \pm 112.82 \mathrm{~ms}$ for girls and 833, $09 \pm 102.36 \mathrm{~ms}$ for boys).When performing the 100 tests, while sporting children have a better RT than the non-sporting children $(711.83 \pm 31.05 \mathrm{~ms}$ in sporting, compared to $783.48 \pm 98.46 \mathrm{~ms}$ in nonsporting), differences in girls were not significant ( $\mathrm{p}>0.05)$. A possible explanation for this may be better mobilization of non-sporting when they were told that their results will be compared with those of sporting. Although other authors studied by us [6] mention in their works that not always the results of the sporting persons are significantly better than those of the non-sporting ones, yet their explanations are of a different nature; they put this 'lack of significance' on account of the past experience of the non-sporting persons (the fact that they practiced a sport in childhood, they were part of the school team, etc.). However, in most of the papers studied $[5],[6],[12]$ the authors pronounce in favour of the sporting persons.

In order to carry out the following comparisons (Table 3), the 100 tests were divided into two groups of 50, as follows: the first group of 50, including the tests from 1 to 50 and the second group of 50, which included tests from 51 to 100 . The RT average obtained for these two groups were compared to those of the 50 test series. It was observed that regardless of gender, the non-sporting group had significantly better RT values for both the first $50(\mathrm{p}<0.01)$ and the second group $(\mathrm{p}<0.01)$. There was no explanation for this result.

In the group of sporting persons, the evolution is quite different: while in the first comparison (50 test series and the first group of 50) there are no significant differences ( $p>0.05$ ), in boys the result is in favour of the first group of $50(p<0.05)$. In the second comparison $(50$ test series and the second group of 50), the results are in favour of a series of 50 tests in both girls and boys $(\mathrm{p}<0.01)$. The explanation might be the following: due to the fatigue accumulated during the 100 tests, the subjects' ability to concentrate decreases, resulting in a longer RT. This decrease in the concentration capacity could be attributed to the fact that accommodation with the device consisted only in the execution of 50 tests, not in the execution of a series of 100 tests.

Regarding the sequential testing (Table 4), for the same kind of comparisons, the differences are significant in favour of the groups of 50 [both the first and the second] in both girls and boys $(\mathrm{p}<0.01)$. This can be attributed to breaks between sequences. Although the subjects argue that this type of test is boring, following the results the 100 test series may seem 'easier', meaning that participants do not have to focus for a longer time (as in series of 100 consecutive tests). 
In the group of sporting persons, comparisons were made between continuous and sequential series. The results were somewhat unexpected: in girls between the 50 test series, there were significant differences in continuous testing $(\mathrm{p}<0.05)$, while in boys the difference was insignificant ( $p>0.05)$. With regard to the 100 test series, the differences recorded are significant in both girls and boys, therefore in favour of sequential testing ( $p$ $<0.01)$. The fact that the significant difference is in favour of sequence testing can be explained, as we have shown above, in that in continuous testing, due to accumulated fatigue, subjects lose their ability to concentrate, and developing the right response lasts longer; while in sequential testing, due to breaks between them, the fatigue-induced effect is somewhat removed, the execution being faster.

Comparing the results broken down into 10 test sequences showed that there were no significant differences either in the type of testing (continuous or sequential), nor between the sequences of the same test $(\mathrm{p}>$ $0.05)$.

Although in our study the values obtained by the sporting persons are better than those of the non-sporting ones, comparing them with values from other studies [10] reveals that they are much lower than those of the others $(651.25 \pm 52.14 \mathrm{~ms}-720.82 \pm 108.82 \mathrm{~ms}$ in girls and $662.82 \pm 66.42$ $\mathrm{ms}-833.09 \pm 102.36 \mathrm{~ms}$ in boys, compared to $165-255 \mathrm{~ms}$ in them).

Explanations can be as follows:

- age difference (12 -14 years old to us compared to 21,6 years old to them);

- Proteau's subjects [10] were constantly showing the likelihood of the stimulus, while the subjects of the present study, were not; and

- Proteau's subjects [11] had a choice between two situations, while our subjects had to choose from four situations. The complexity of task, and in relation to age, was much greater to us.

Compared to our previous study, girls achieved lower RT values (663.35 msnow compared to $692.43 \mathrm{~ms}$ ), while boys were at the same level (694.68 ms now compared to $697.09 \mathrm{~ms}$ ).

The results obtained by our handball players were compared with those of another group of athletes (female handball players, age 16-17, training years: 4 years) [1]. Although the age and seniority of the female players of Covrig's study [1] were higher than those of our group, however, RT average was significantly better in our girls $(\mathrm{p}<0.05)$. We cannot say the same thing about RT of boys ( $\mathrm{p}>0.05)$.

It is important to mention that Covrig's study [1] used the same device as in this study. The only difference was the number of tests that 
subjects had to perform: 30 - in Covrig's study [1] and, 50 and 100 in this study.

\section{Conclusions}

A first conclusion would be that sporting persons have better RT results than non-sporting persons, irrespective of gender.

A second conclusion is that there are no significant differences between girls and boys, both sporting and non-sporting persons.

And the third conclusion: breakdown by series of 10 testsproved to be effective in long-term testing (100 tests), during which the subjects were no longer required to focus for a longer time than for continuous testing.

\section{References}

[1] Covrig N. Contributii la îmbunatatirea declansarii contraatacului în handbal. 2000; unpublished graduation thesis.

[2] Demeter A. Bazele fiziologice si biochimice ale calitatilor motrice. Bucharest: Editura Sport-Turism; 1981, pp. 37-40.

[3] Gidu D. Timpul de reactievizual cu alegere la handbalistiiîncepatori.Sesiunea de ReferatesiComunicariStiintifice a CadrelorDidactice.2000April 22. Constanta.

[4] Harbin G, Durst L, Harbin, D. Evaluation of oculomotor response in relationship to sport performance. Med. Sci. Sp. and Ex. 1989; 21(3): 258-262.

[5] McMorris T, Beazeley A. Performance of experienced and inexperienced soccer players on soccer specific tests of recall, visual search and decisionmaking. J.of Hum. Mov. Stud. 1997; 33:1-13.

[6] McMorrisT, GraidonJ. The effect of exercise on the decision-making performance of experienced and inexperienced soccer players. Res. Quarterly for Ex. and Sp. 1996; 67(1):109-114.

[7] Mitra G,Mogos A.Dezvoltareacalitatilormotrice.Bucharest:Editura SportTurism; 1977. pp. 77-82.

[8] Muşat G, Petcu D, Popa C, Ochiuleț D. Identification standard and nonstandard exercises for multilateral physical training to soccer players beginners.Ovidius University Annals, Series Physical Education and Sport/Science, Movement and Health.2014; 14(2): 487-494.

[9] Proteau L, Alain G. La difference de pente du temps de reaction au choix en fonction du mode de presentation des stimuli: Le role des effets de sequence. Rev. Can. de Psych. 1982; 36(4): 576-585.

[10] Proteau L. La difference de temps de reaction au choixobservee pour chaquepaire stimulus-response dansunetache a huit evenements equiprobables. Rev. Can. de Psych. 1985; 39(3): 440-448. 
Diana Victoria GIDU \& ... | Lumen Proceedings 12 | SEC-IASR 2019

[11] Proteau L, Dionne L. Faire un choix entre deux directions et choisir entre produireou non une response: est-ceuneseule meme tache?.Chaiers de Psych. Cog. 1982; 2(1): 19-29.

[12] Proteau L, Dugas G.Strategie de decision d'unegrupe de jouers de basket-ball inter -universitaire. Can.J.Appl.Spt.Sci. 1982; 7(2):127-133. 